\title{
Energetic Macroscopic Representation of an Electrically Heated Building with Electric Thermal Storage and Heating Control for Peak Shaving
}

\author{
Cristina Guzman, Kodjo Agbossou, Alben Cardenas \\ Hydrogen Research Institute and The “Département de Génie Électrique et Génie Informatique”, Université du \\ Québec à Trois-Rivières, Trois-Rivières, Canada \\ Email: guzman@uqtr.ca, kodjo.agbossou@uqtr.ca, cardenas@uqtr.ca
}

Received 11 February 2015; accepted 13 April 2015; published 14 April 2015

Copyright (C) 2015 by authors and Scientific Research Publishing Inc.

This work is licensed under the Creative Commons Attribution International License (CC BY).

http://creativecommons.org/licenses/by/4.0/

(c) (i) Open Access

\section{Abstract}

As a part of the Smart Grid concept, an efficient energy management at the residential level has received increasing attention in lately research. Its main focus is to balance the energy consumption in the residential environment in order to avoid the undesirable peaks faced by the electricity supplier. This challenge can be achieved by means of a home energy management system (HEMS). The HEMS may consider local renewable energy production and energy storage, as well as local control of some particular loads when peaks mitigation is necessary. This paper presents the modeling and comparison of two residential systems; one using conventional electric baseboard heating and the other one supported by Electric Thermal Storage (ETS); the ETS is employed to optimize the local energy utilization pursuing the peak shaving of residential consumption profile. Simulations of the proposed architecture using the Energetic Macroscopic Representation (EMR) demonstrate the potential of ETS technologies in future HEMS.

\section{Keywords}

Home Energy Management, Energetic Macroscopic Representation, Building Modeling, Electric Thermal Storage

\section{Introduction}

Smart grid concept brings within the scope of implementing more efficient and performing technologies to im-

How to cite this paper: Guzman, C., Agbossou, K. and Cardenas, A. (2015) Energetic Macroscopic Representation of an Electrically Heated Building with Electric Thermal Storage and Heating Control for Peak Shaving. Energy and Power Engineering, 7, 144-153. http://dx.doi.org/10.4236/epe.2015.74014 
prove the electricity system. Modern and attractive technologies would also motivate residential clients to become managers of their own consumption as a better way for the energy use [1].

Local energy production systems, local energy storage and residential load management are new challenges pursuing the efficiency improvement of the grid without the stress engendered by the unbalance between energy production and consumption. Among the many initiatives to improve the residential energy efficiency and commercial buildings, some of them propose local renewable electricity generation as photovoltaic, and electrical or thermal local storage systems [2]-[4].

Electric Thermal Storage (ETS) systems are inspired from an ancient technology used by aboriginal arctic populations, which employed heated stones as storage medium. This technology has lately emerged as a good option to improve the energy utilization, and can be employed for water-heating systems, space heating/cooling systems of buildings and off-peak electricity storage systems [5]-[8]. In the residential environment this option is quite easy to carry out, however some limitations and rejection arise taking into account, the space and the quite high weight of such storage systems. In sensible heat technologies [9] [10], when water heater is employed as storage medium, the temperature must remain between $60^{\circ} \mathrm{C}$ and $82^{\circ} \mathrm{C}\left(140^{\circ} \mathrm{F}-180^{\circ} \mathrm{F}\right)$. Otherwise when solid materials are employed, as ceramic and brick, temperatures can go up to $700^{\circ} \mathrm{C}\left(1300^{\circ} \mathrm{F}\right)$. In latent heat technologies phase change materials (PCM) are employed which permit to store heat using a narrow temperature range without employing high temperatures [11]-[13].

Electric Thermal Storage (ETS) typically use high density ceramic bricks as storage element. The bricks are placed inside a cabinet which can weight hundreds of pounds [14]. For residential use, ETS is well adapted to be supplied by renewable energy local generation (as photovoltaic or wind power) or taking advantage of cheap off-peak power [15]. The use of ETS might be a good alternative to shave the unwanted peak of energy consumption, when this peak is mostly caused by the heating utilization and, can be appropriate for cold climate countries like Canada. As matter of facts, it could be a practical choice taking into account that heating power represents more than $60 \%$ of energy consumption in Canadian residential buildings.

The Energetic Macroscopic Representation (EMR) has been introduced as a graphical descriptor approach offering a macroscopic energetic view of multiphysics system [16]-[18]. EMR offers an inversion-based control contributing to the controller design and the implementation of energy management strategies.

This paper presents the development of the EMR of a residential system with electric thermal storage. The main parts of the system have been represented and a simulation model has been implemented by using MATLAB/ Simulink. Simulation results using a classic management strategy show the potential of the electric thermal storage for peak shaving during winter grid peak periods. The remainder of this paper is organized as follows, Section 2 presents the EMR of the studied system; Section 3 presents the simulation results for a system with and without electric thermal storage; and the conclusion of the paper will be presented in Section 4.

\section{EMR of Residential System with Electric Thermal Storage}

\subsection{General Description of Studied System}

The studied system consists of an electrically heated detached house. In the base case, the system comprises the Electric Heating System (EHS) composed of resistive baseboards, represented as a single aggregated unit and the critical loads. A second case considers additionally the use of Electric Thermal Storage (ETS) as illustrated in Figure 1. The modeling of the thermal envelope of the building and the behavior of the external and the internal temperatures are important features in the management of this kind of systems which become essentials for the study.

Figure 2 represents a simplified view of the energetic macroscopic representation of the residential system, which is coupled to the utility grid as the main Energy Source (ES). Through the distribution panel three subsystems are connected: the Space Heating System (SHS), the Electric Thermal Storage (ETS) and the Critical Loads (water heater, lighting and home appliances). The subsystems are denoted DS-1, DS-2 and DS-3 respectively.

The utility grid is represented as the electric source ES, the utility voltage and main current are denoted as $U_{G}$ and $I_{G}$ respectively. The main current of the system is represented by:

$$
I_{G}=I_{L}+I_{H}+I_{S}
$$

where, $I_{L}$ is the current of critical loads, $I_{H}$ is the current of the SHS and $I_{S}$ is the current of the ETS. As il- 


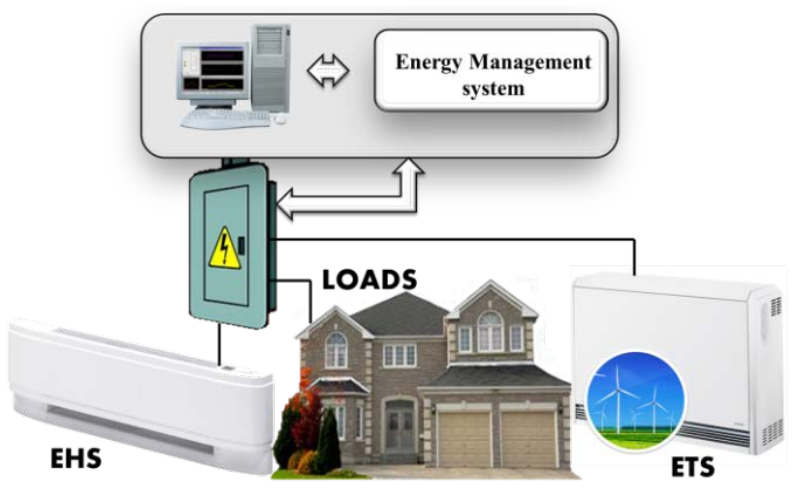

Figure 1. Simplified EMR representation of residential system with electric thermal storage.

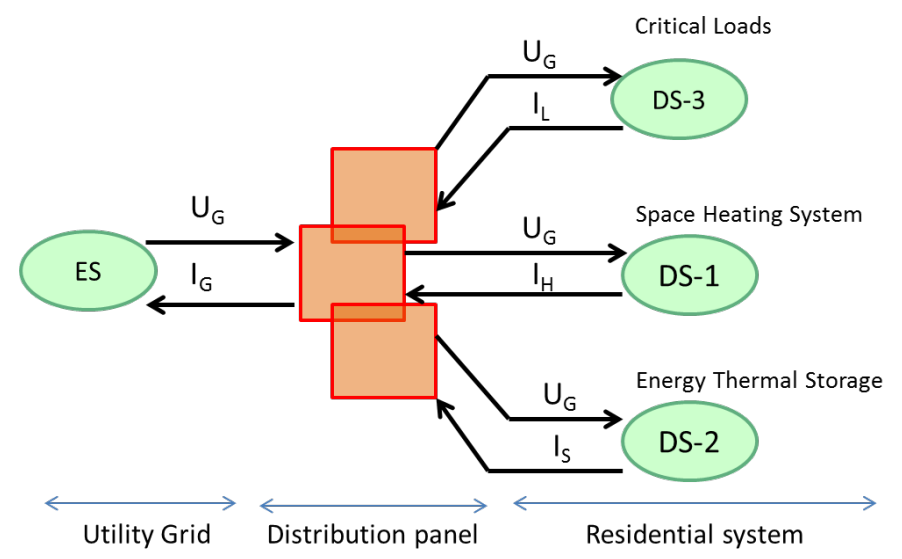

Figure 2. Simplified EMR representation of residential system with electric thermal storage.

lustrated in Figure 2 the distribution panel is modeled as a coupling block, and the voltages applied to each subsystem are the action variables, in counterpart the currents are the reaction variables.

\subsection{Space Heating System}

Residential heating systems in Quebec are essentially electric systems, and in this study it is supposed that all heating needs are supplied from the electric source. The EMR representation of the SHS is depicted by Figure 3, there, the Electric Heater, normally an assembly of baseboard systems, is controlled by means of a thermostatic control which is connected to the voltage source. The control signal of the thermostatic control is called $m_{1}$ and permits to modulate the power sent to the baseboard assembly. The mean voltage applied to the electric heater $\left(U_{\mathrm{SH}}\right)$ is defined by

$$
U_{\mathrm{SH}}=m_{1} \cdot U_{G}
$$

The reaction to the applied voltage is the current $I_{\mathrm{SH}}$ which is defined by

$$
I_{\mathrm{SH}}=\frac{U_{\mathrm{SH}}}{R_{\mathrm{SH}}}
$$

where, $R_{\mathrm{SH}}$ is the equivalent electric resistance of the electric heater assembly. Then, the current from the main source $\left(I_{H}\right)$ can be defined by

$$
I_{H}=I_{\mathrm{SH}} \cdot m_{1}
$$

Notice that the electric heater is represented by a multi-physical conversion element. This representation because, the left side there is an electric system and at the right side there is a thermal system. According to the 


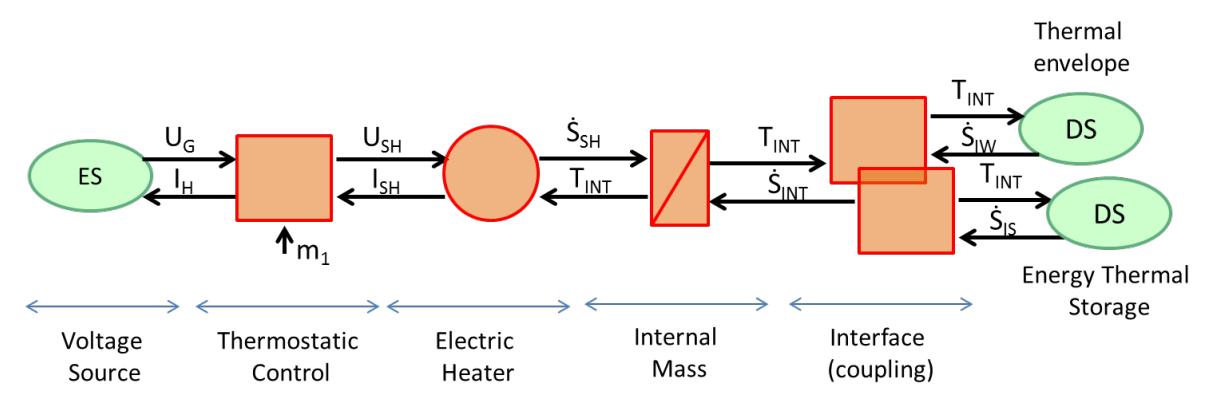

Figure 3. EMR representation of residential space heating system (SHS).

second law in thermodynamics conservation the entropy flow rate $\dot{S}$ is found [19]. Then, the power at each side of this block can be computed as

$$
I_{\mathrm{SH}} \cdot U_{\mathrm{SH}}=\dot{S}_{\mathrm{SH}} \cdot T_{\mathrm{INT}}
$$

where, $\dot{S}_{\mathrm{SH}}$ is the entropy flow rate of heating in $\left[\mathrm{W} /{ }^{\circ} \mathrm{K}\right]$ and $T_{\mathrm{INT}}$ is the internal temperature of the residential building in [ $\left.{ }^{\circ} \mathrm{K}\right]$.

An energy storage element is employed to represent the internal thermal mass of the building (internal walls, air mass and home furniture). The differential equation of the internal thermal mass and the internal temperature $\left(T_{\mathrm{INT}}\right)$ can be written as

$$
T_{\mathrm{INT}}\left(\dot{S}_{\mathrm{SH}}+\dot{S}_{\mathrm{INT}}\right)=m C p_{\mathrm{IM}} \cdot \dot{T}_{\mathrm{INT}}
$$

where

$$
\dot{T}_{\mathrm{INT}}=\frac{\mathrm{d}}{\mathrm{d} t} T_{\mathrm{INT}} \text {, and } m C p_{\mathrm{IM}} \text { is the heat capacity of the internal thermal mass in }\left[\mathrm{W} \cdot \mathrm{s} /{ }^{\circ} \mathrm{K}\right] \text {. The output entropy }
$$
flow rate is defined by

$$
\dot{S}_{\mathrm{INT}}=\dot{S}_{\mathrm{IW}}+\dot{S}_{\mathrm{IS}}
$$

where $\dot{S}_{\mathrm{IW}}$ is the entropy flow rate from the internal side of the walls (coming from the thermal envelope), and $\dot{S}_{\text {IS }}$ is the entropy flow rate from the energy thermal storage system.

It is to remark that in the coupling system three entropic flow rates are defined, the first for the internal thermal mass, the second for the thermal envelope and the third one for the ETS. A common temperature is at the three sides of coupling block corresponding to the internal temperature of the residential building.

\subsection{Building Thermal Envelope}

Canadian homes are built using materials with high thermal resistance looking to reduce the heat losses during winter time. These construction characteristics impose a modeling of the walls as a resistive part (thermal insulation) and a thermal capacity part. The EMR of the building envelope is depicted in Figure 4. There, the internal layer of walls is represented by a mono-physical conversion element connecting the interior of the building (internal thermal mass) and the thermal mass of the walls. The power at each side of the conversion block are defined by

$$
\begin{gathered}
\dot{S}_{\mathrm{IW}} \cdot T_{\mathrm{INT}}=\dot{S}_{W} \cdot T_{\mathrm{WM}} \\
\dot{S}_{\mathrm{IW}} \cdot T_{\mathrm{INT}}=\frac{\left(T_{\mathrm{WM}}-T_{\mathrm{INT}}\right)}{R_{\mathrm{IW}}} \\
\dot{S}_{W} \cdot T_{\mathrm{WM}}=\frac{\left(T_{\mathrm{INT}}-T_{\mathrm{WM}}\right)}{R_{\mathrm{IW}}}
\end{gathered}
$$

where, $\dot{S}_{\text {IW }}$ is the entropy flow rate from internal layer of walls to the internal thermal mass; $\dot{S}_{W}$ is the entropy flow rate to the thermal mass of the walls from the internal layer of the walls. $R_{\mathrm{IW}}$ is the equivalent thermal resistance of the internal side layer of walls. 


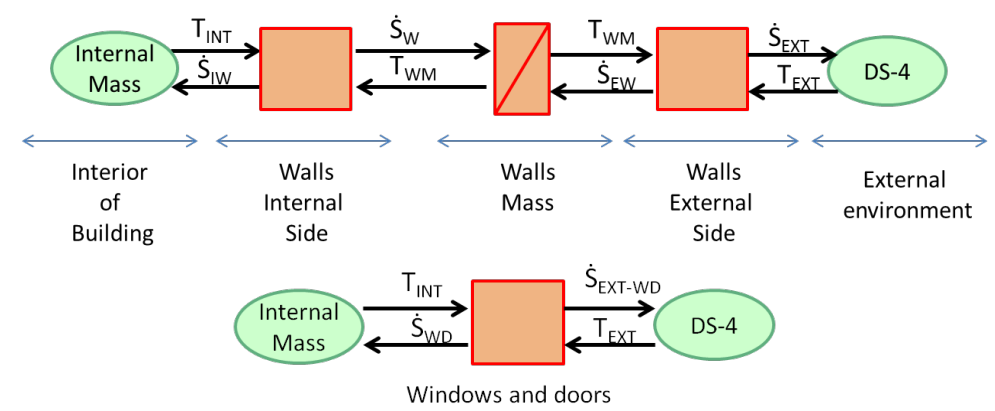

Figure 4. EMR representation of building thermal enveloppe.

The thermal mass of the walls is represented by an energy storage element connected to the internal and external layers of the walls; the differential equation of this storage element can be written as

$$
T_{\mathrm{WM}}\left(\dot{S}_{W}+\dot{S}_{\mathrm{EW}}\right)=m C p_{\mathrm{WM}} \cdot \dot{T}_{\mathrm{WM}}
$$

where, $\dot{S}_{\mathrm{EW}}$ is the entropy flow rate from external layer of the walls, $T_{\mathrm{WM}}$ is the temperature inside the walls; $m C p_{\text {WALL }}$ is the heat capacity of the walls mass.

The external layer of the walls, like the internal one, is also represented by a mono-physical conversion element with an equivalent thermal resistance denoted $R_{\mathrm{EW}}$. This element connects the thermal mass of the walls with the external environment. The external environment which imposes a variable temperature $\left(T_{\mathrm{EXT}}\right)$ is denoted as DS-4 in Figure 3. Then, the power at each side of the conversion element can be written as

$$
\dot{S}_{\mathrm{EW}} \cdot T_{\mathrm{WM}}=\dot{S}_{\mathrm{EXT}} \cdot T_{\mathrm{EXT}}
$$

The entropy flow rate to the environment $\left(\dot{S}_{\mathrm{EXT}}\right)$ is defined by the difference of temperature between the walls and the environment, and can be written as

$$
\dot{S}_{\mathrm{EXT}}=\frac{\left(T_{\mathrm{WM}}-T_{\mathrm{EXT}}\right)}{T_{\mathrm{EXT}} \cdot R_{\mathrm{EW}}}
$$

The windows and doors are represented as a mono-physical conversion element, as the resistive layers of the walls. The power at each side of the conversion element can be written as

$$
\dot{S}_{\mathrm{WD}} \cdot T_{\mathrm{INT}}=\dot{S}_{\mathrm{EXT}-\mathrm{WD}} \cdot T_{\mathrm{EXT}}
$$

The entropy flow rate to the environment $\left(\dot{S}_{\text {EXT-WD }}\right)$ is defined by the difference of internal mass temperature and the environment, and can be written as

$$
\dot{S}_{\mathrm{EXT}-\mathrm{WD}}=\frac{\left(T_{\mathrm{INT}}-T_{\mathrm{EXT}}\right)}{T_{\mathrm{EXT}} \cdot R_{\mathrm{WD}}}
$$

where $R_{\mathrm{WD}}$ corresponds to the equivalent thermal resistance of the doors and windows.

\subsection{Electric Thermal Storage System}

The electric thermal storage system normally consists of a heat storage control, an electric heater (heating element), a thermal mass, and a heating blower (forced air heating). The EMR of this subsystem is depicted in Figure 5. The heat storage control permits to modulate the voltage applied to the electric heater according to a modulation index $m_{2}$. In most of cases, $m_{2}$ is considered a binary input which imposes an ON/OFF control of the electric heater. The voltage and currents of the control block can be defined by

$$
\begin{gathered}
U_{\mathrm{ETS}}=m_{2} \cdot U_{G} \\
I_{\mathrm{ETS}}=\frac{U_{\mathrm{ETS}}}{R_{\mathrm{ETS}}} \\
I_{S}=I_{\mathrm{ETS}} \cdot m_{2}
\end{gathered}
$$




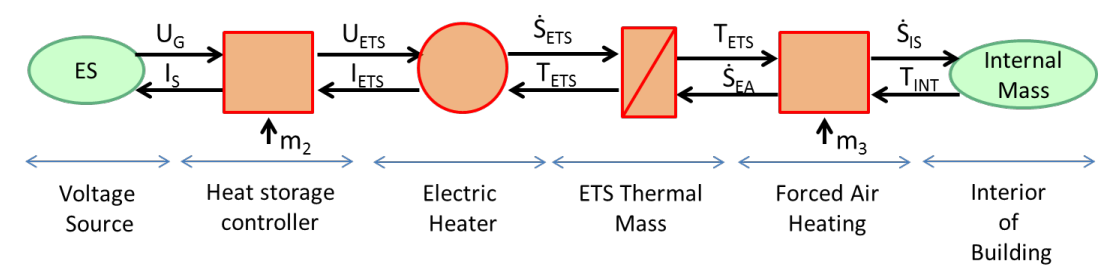

Figure 5. EMR representation of the electric thermal storage system (ETS).

As in the space heating system case, the electric heater is modeled as a multi-physical conversion element. The differential equation of this element can be written as

$$
\begin{gathered}
T_{\mathrm{ETS}}\left(\dot{S}_{\mathrm{ETS}}+\dot{S}_{\mathrm{EA}}\right)=m C p_{\mathrm{ETS}} \cdot \dot{T}_{\mathrm{ETS}} \\
\dot{T}_{\mathrm{ETS}}=\frac{\mathrm{d}}{\mathrm{d} t} T_{\mathrm{ETS}}
\end{gathered}
$$

where $m C p_{\mathrm{ETS}}$ is the heat capacity of the thermal mass of the storage system. $\dot{S}_{\mathrm{ETS}}$ is the entropy flow rate from the electric heater; $-\dot{S}_{\mathrm{EA}}$ is the entropy flow rate from the storage system (transferred to the internal mass of the building).

The forced air heating system is modeled similarly to the heat storage control, that's as a mono-physical conversion element. The input and output powers can be written as

$$
\dot{S}_{\mathrm{EA}} \cdot T_{\mathrm{ETS}}=\dot{S}_{\mathrm{IS}} \cdot T_{\mathrm{INT}}
$$

The heating power transferred from the ETS to the internal mass of the building is controlled by means of the input $m_{3}$ and the nominal heating power $\left(P_{\mathrm{BH}}\right)$; a constant power representing the heat leaks of the storage system $\left(P_{\mathrm{HL}}\right)$ is also included using

$$
\dot{S}_{\mathrm{IS}} \cdot T_{\mathrm{INT}}=P_{\mathrm{HL}}+m_{3} P_{\mathrm{BH}}
$$

\subsection{Critical Loads}

As illustrated in Figure 2 critical loads are considered in the system. They are simulated using hourly typical residential profiles of energy consumption, measured from a Quebec residence by means of a commercial energy monitoring system [20]. The total current of critical loads $I_{L}$ is computed using the load profile and the input voltage. The complete EMR of the studied residential system with ETS is presented in Figure 6, where all the explained modeled subsystems are coupled.

\section{Simulation Results}

The system described in previous section has been implemented in MATLAB/Simulink. Two systems have been implemented, one including the ETS and the other without it, as illustrated in Figure 7, the two systems have similar characteristics and their parameters are presented in Table 1. These parameters correspond to a single family house (detached house) of Quebec as explained before. It is to remark that only the temperature effect has been studied being the most important parameter for this Nordic locations; e.g. solar radiation gains and internal gains have been neglected.

For simulation purposes a classic proportional and integral (PI) controller is employed to control the internal temperature which is set to $21^{\circ} \mathrm{C}$ during the day period (from $6 \mathrm{H}$ to $22 \mathrm{H}$ ) and at $19.5^{\circ} \mathrm{C}$ at night. The proportional and integral gains of controllers are also presented. The external temperature used in this study has been obtained from the SIMEB Hydro-Quebec website [21] for the winter period of 2013-2014 (November 2013 to April 2014).

The ETS is controlled considering the "heat storage" at "off-peak periods" and the "heat discharge" at peak period; in the "off-peak period" the load current at the distribution panel is measured and used to obtain the total power of the residential building, then the storage power is computed according to the actual power not exceeding $6 \mathrm{~kW}$. The storage is enabled from November to March, months during which larger amount of heating is usually required. The "peak period" is considered fixed for weekdays between $6 \mathrm{H}$ and $10 \mathrm{H}$ and between $16 \mathrm{H}$ 


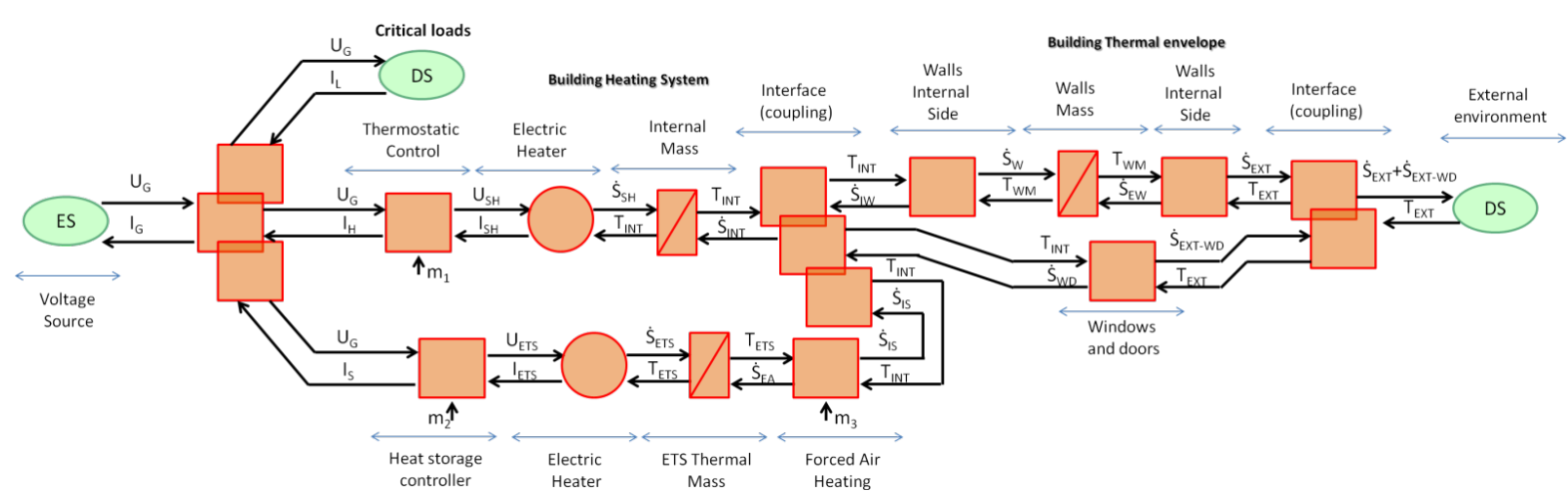

Figure 6. EMR representation of residential system with electric thermal storage.

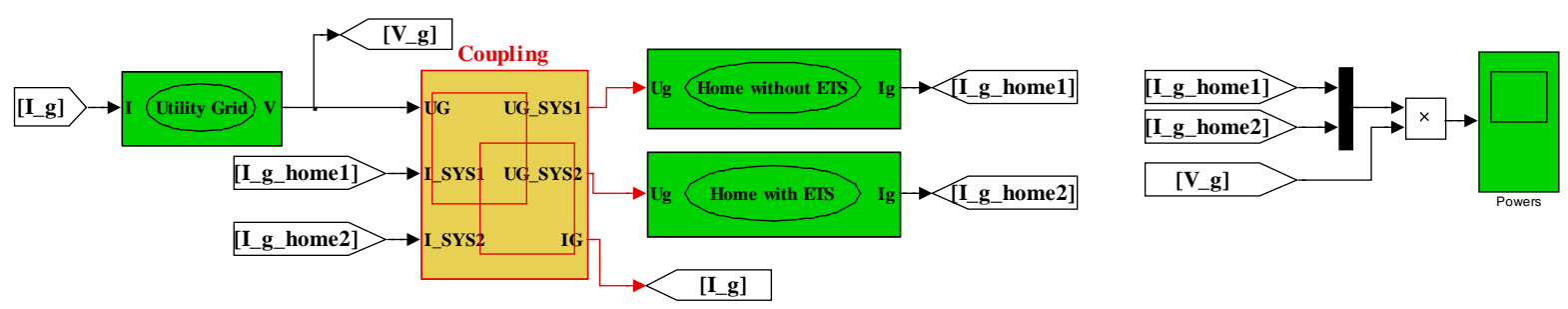

Figure 7. Model implemented in Simulink/MATLAB.

Table 1. System parameters.

\begin{tabular}{ccc}
\hline Description & Value & Units \\
\hline Voltage source & 240 & $\mathrm{~V}$ \\
Building envelope & & $\mathrm{MW} \cdot \mathrm{s} /{ }^{\circ} \mathrm{K}$ \\
$m C p_{\mathrm{WALL}}$ & 107.53 & ${ }^{\circ} \mathrm{K} / \mathrm{W}$ \\
$R_{\mathrm{IW}}$ & 0.0127 & ${ }^{\circ} \mathrm{K} / \mathrm{W}$ \\
$R_{\mathrm{EW}}$ & $3.719 \mathrm{e} 5$ & ${ }^{\circ} \mathrm{K} / \mathrm{W}$ \\
$R_{\mathrm{WD}}$ & 0.0301 & \\
Electric thermal storage & & $\mathrm{kW} \cdot \mathrm{s} /{ }^{\circ} \mathrm{K}$ \\
$m C p_{\mathrm{ETS}}$ & 12,240 & $\mathrm{~W}$ \\
$P_{\mathrm{HL}}$ & $2 \times 3400 \times 0.1$ & $\mathrm{~W}$ \\
$P_{\mathrm{BH}}$ & $8400 \times 0.9$ & $\Omega$ \\
$R_{\mathrm{ETS}}$ & & \\
Space heating system & 6904.7 & $\mathrm{~kW} \cdot \mathrm{s} /{ }^{\circ} \mathrm{K}$ \\
$m C p_{\mathrm{IM}}$ & 10 & $\mathrm{~kW}$ \\
$P_{\mathrm{SH}}$ & 5.76 & $\Omega$ \\
$R_{\mathrm{SH}}$ & & $\mathrm{W} /{ }^{\circ} \mathrm{K}$ \\
$K p$ & 852 & $\mathrm{~W} /{ }^{\circ} \mathrm{K} \mathrm{rad} / \mathrm{s}$ \\
$K i$ & 8.52 &
\end{tabular}

and $20 \mathrm{H}$, weekend period is considered off-peak. During the "peak period" the internal temperature of the building is controlled by means of two PI controllers, one driving the ETS and the other one driving the classic space heating system.

Simulation results are plotted in Figures 8-10, where Figure 8 presents the internal and external temperature during the simulation period (November 2013 to April 2014) and the total power of the two systems; it is to re- 

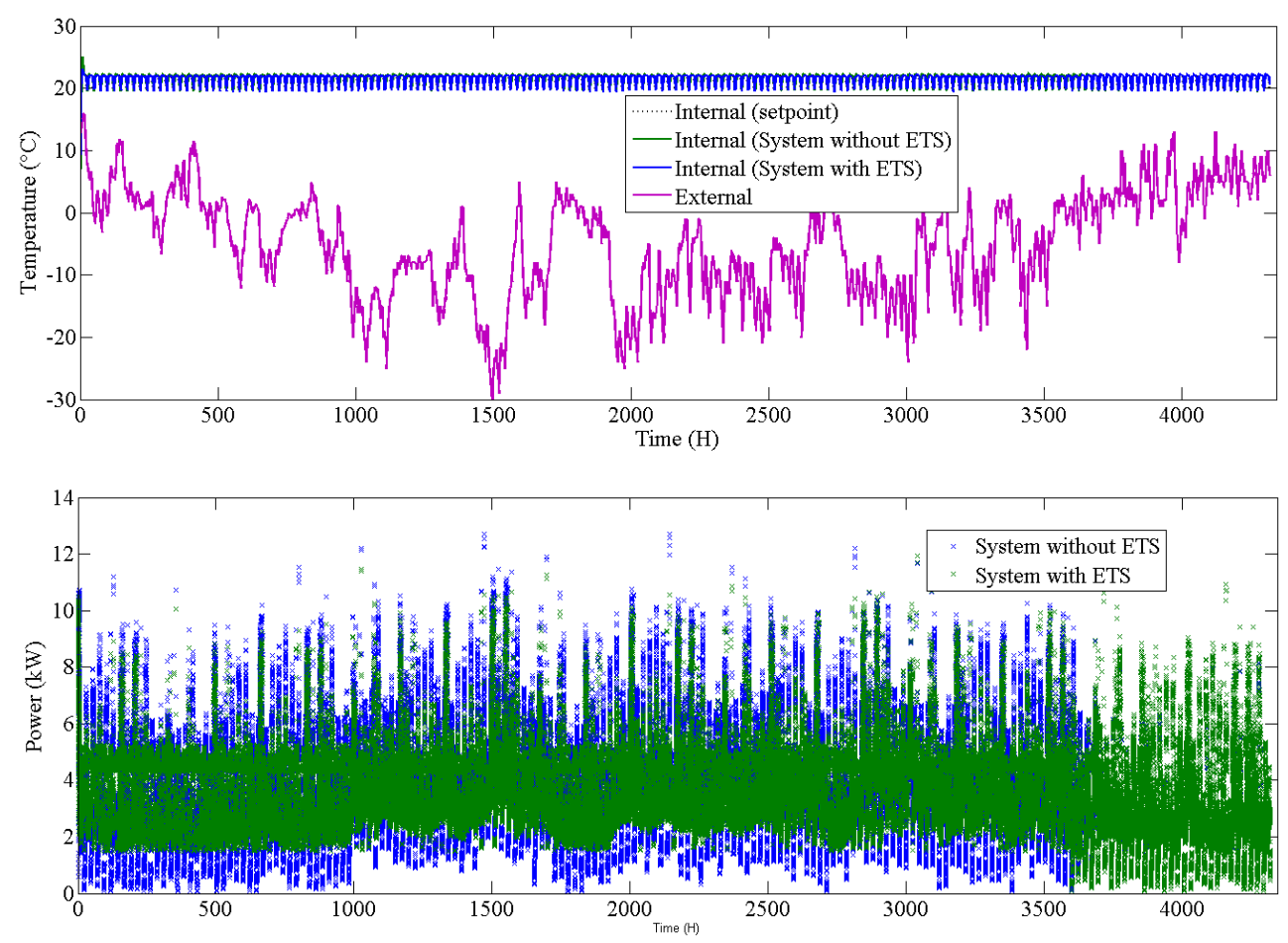

Figure 8. External temperature at Trois-Rivieres Canada and instantaneus power of each simulated residential building (from November 2013 to April 2014).
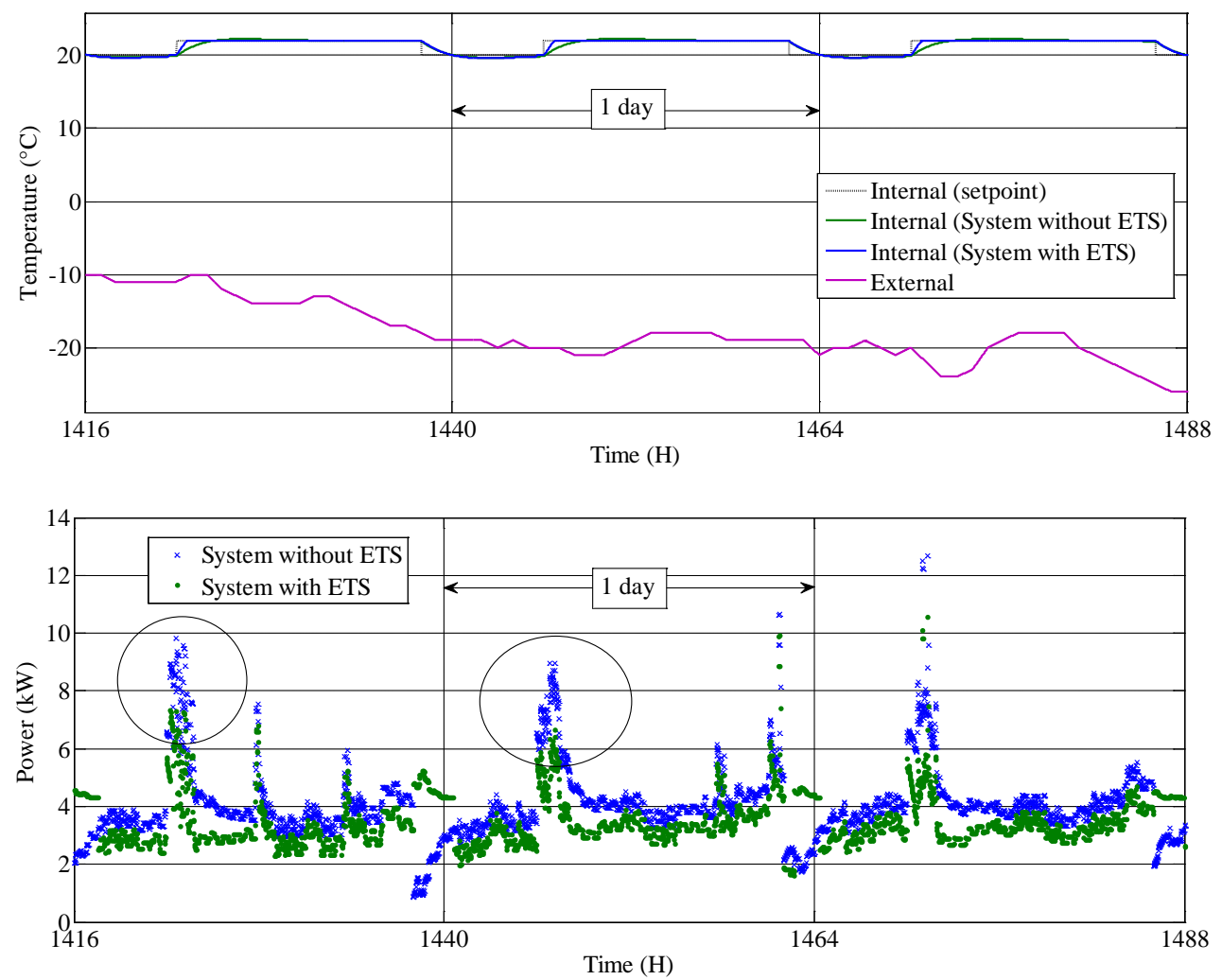

Figure 9. External temperature at Trois-Rivieres Canada and instantaneus power of each simulated residential building (3 days on January 2014). 


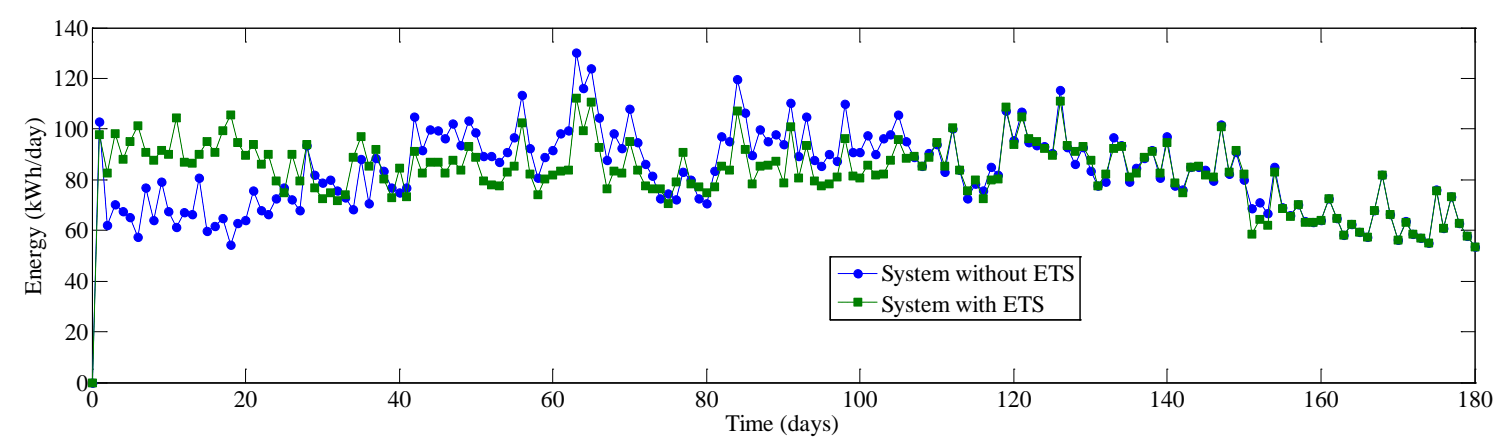

Figure 10. Energy consumption of each simulated residential building (from November 2013 to April 2014).

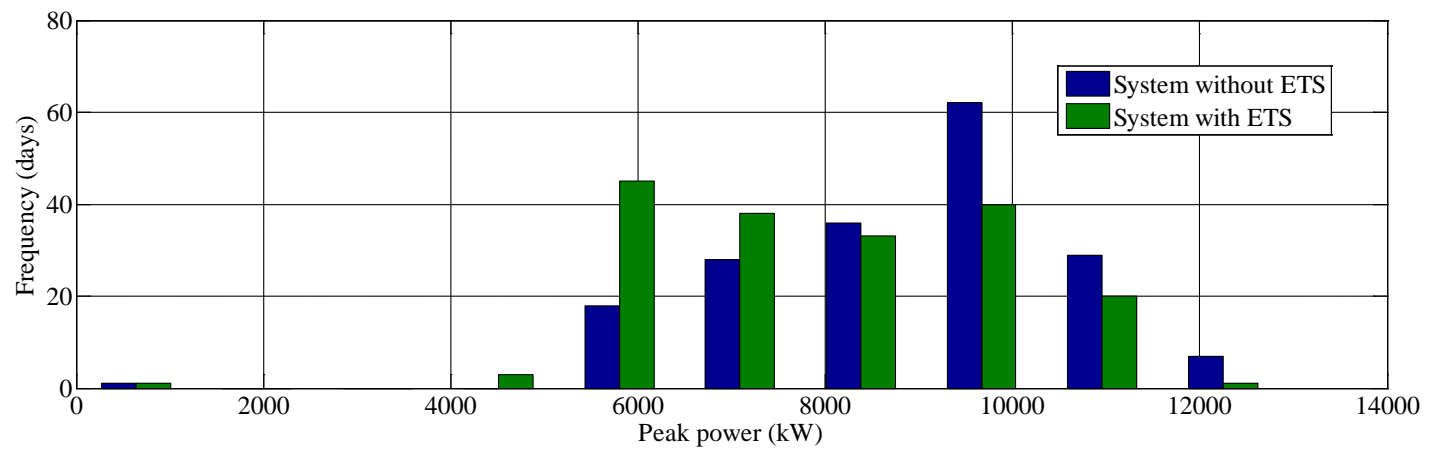

Figure 11. Distribution of peak power for each simulated residential building (from November 2013 to April 2014).

mark that the coldest period corresponds to the January and February months. Results corresponding to 3 days of cold period (January 2014) are plotted in Figure 9. It is observed that the peak of consumption is shaved using the electric thermal storage while the control of temperature is maintained. Morning peaks are encircled in Figure 9 in order to better illustrate the peak shaving. In Figure 10 the total energy consumption in $\mathrm{kWh} / \mathrm{day}$ is plotted, showing that the peak of daily energy in the coldest period is also smoothed. Notice that the two systems use the same energy during the simulation period. The distribution of peak power per day for each system is presented in Figure 11, where the maximal frequency appears at $9.67 \mathrm{~kW}$ (62 days) and at $5.8 \mathrm{~kW}$ (45 days) for the system using classic heating and for the one with ETS respectively.

\section{Conclusion}

This paper has presented the modeling of two residential systems: one using conventional electric baseboard heating and the other one supported by Electric Thermal Storage. The models have been built using the Energetic Macroscopic Representation (EMR) which permits the description of multiphysic systems using simple blocks interconnected with power exchanges links. The implemented models, using MATLAB, have permitted to validate the concept of Electric Thermal Storage and its potential for peak shaving; in fact peak power reduction without negative effects on the temperature regulation has been obtained by simulations. This model could be employed to study control strategies for Demand Side Management (DSM).

\section{Acknowledgements}

This work was supported in part by the LTE Hydro-Québec, the "Bureau de l’Efficacité et de l'Innovation Énergétiques du Québec” and Natural Science and Engineering Research Council of Canada.

\section{References}

[1] Kok, K., Karnouskos, S., Ringelstein, J., Dimeas, A., Weidlich, A., Warmer, C., Drenkard, S., Hatziargyriou, N. and Lioliou, V. (2011) Field-Testing Smart Houses for a Smart Grid. 21st International Conference on Electricity Distribution (CIRED), Frankfurt, 6-9 June 2011, 6-9. 
[2] Van Roy, B.J., Verbruggen, B. and Driesen, J. (2013) Ideas for Tomorrow. IEEE Power and Energy Magazine, 11, 7581. http://dx.doi.org/10.1109/MPE.2013.2268815

[3] Molderink, A., Bakker, V., Bosman, M.G.C., Hurink, J.L. and Smit, G.J.M. (2010) Management and Control of Domestic Smart Grid Technology. IEEE Transactions on Smart Grid, 1, 109-119. http://dx.doi.org/10.1109/TSG.2010.2055904

[4] Davito, B., Tai, H. and Uhlaner, R. (2010) The Smart Grid and the Promise of Demand-Side Management. McKinsey on Smart Grid. McKinsey \& Company, Atlanta, 38-44.

[5] Craven, C. and Grunau, B. (2013) Thermal Storage Technology Assessment. Cold Climate Housing Research Center (CCHRC), Alaska Housing Finance Corporation \& the Alaska Department of Commerce, Community, and Economic Development, Fairbanks.

[6] Sharma, A., Tyagi, V.V., Chen, C.R. and Buddhi, D. (2009) Review on Thermal Energy Storage with Phase Change Materials and Applications. Renewable and Sustainable Energy Systems, 13, 318-345.

[7] Science Applications International Corporation (SAIC Canada) (2013) Compact Thermal Energy Storage Technology Assessment Report. Presented to City of Pickering and Natural Resources Canada.

[8] Dincer, I. (2002) On Thermal Energy Storage Systems and Applications in Buildings. Energy and Buildings, 34, 377388. http://dx.doi.org/10.1016/S0378-7788(01)00126-8

[9] Pérez-Lombard, L., Ortiz, J., Coronel, J.F. and Maestre, I.R. (2011) A Review of HVAC Systems Requirements in Building Energy Regulations. Energy and Buildings, 43, 255-268. http://dx.doi.org/10.1016/j.enbuild.2010.10.025

[10] Kulkarni, M.R. and Hong, F. (2004) Energy Optimal Control of a Residential Space-Conditioning System Based on Sensible Heat Transfer Modeling. Building and Environment, 39, 31-38. http://dx.doi.org/10.1016/j.buildenv.2003.07.003

[11] Kiziroglou, M.E., Wright, S.W., Toh, T.T., Mitcheson, P.D., Becker, T. and Yeatman, E.M. (2014) Design and Fabrication of Heat Storage Thermoelectric Harvesting Devices. IEEE Transactions on Industrial Electronics, 61, 302-309. http://dx.doi.org/10.1109/TIE.2013.2257140

[12] Rousse, D.R., Ben Salah, N. and Lassue, S. (2009) An Overview of Phase Change Materials and Their Implication on Power Demand. 2009 IEEE Electrical Power \& Energy Conference (EPEC), Montreal, 22-23 October 2009, 1-6. http://dx.doi.org/10.1109/EPEC.2009.5420979

[13] Kaplan, F., De Vivero, C., Howes, S., Arora, M., Homayoun, H., Burleson, W., Tullsen, D. and Coskun, A.K. (2014) Modeling and Analysis of Phase Change Materials for Efficient Thermal Management. 32nd IEEE International Conference on Computer Design (ICCD), Seoul, 19-22 October 2014, 256-263.

[14] Steffes Corporation, Owner's and Installer's Manual for Room Heating Units-2100 Series. http://www.steffes.com

[15] Armaroli, N. and Balzani, V. (2006) The Future of Energy Supply: Challenges and Opportunities. Angewandte Chemie International Edition, 46, 52-66. http://dx.doi.org/10.1002/anie.200602373

[16] Chen, K. (2010) Common Energetic Macroscopic Representation and Unified Control Structure for Different Hybrid Electric Vehicles. PhD Dissertation, École Doctorale des Sciences pour l’Ingénieur, Université Lille 1.

[17] University of Lille 1, Energetic Macroscopic Representation Web Site. http://www.emrwebsite.org/energetic-macroscopic-representation.html

[18] Horrein, L., Bouscayrol, A. and El-Fassi, M. (2012) Thermal Energetic Model of an Internal Combustion Engine for Simulation of a Thermal Vehicle. 2012 IEEE Vehicle Power and Propulsion Conference (VPPC), Seoul, 9-12 October 2012, 978-983. http://dx.doi.org/10.1109/VPPC.2012.6422768

[19] Dong, Y., El-Bakkali, A., Descombes, G., Feidt, M. and Périlhon, C. (2012) Association of Finite-Time Thermodynamics and a Bond-Graph Approach for Modeling an Endoreversible Heat Engine. Entropy, 14, 642-653. http://dx.doi.org/10.3390/e14040642

[20] Technical Specifications of TED Pro Energy Monitoring and Control System, Rev 7.1, TED the Energy Detective. http://www.theenergydetective.com/5000docs

[21] SIMEB Web Site, Simulation énergétique des bâtiments. https://www.simeb.ca 